\title{
The problems of peculiarity regeneration of architectural-spatial environment of demolished cities
}

\author{
Dalar Babakhanyans ${ }^{1, *}$ \\ ${ }^{1}$ NUACA, Chair of Theory of Architecture, Restoration and Reconstruction of Historical- \\ Architectural Heritage, Fine Arts and History, Yerevan, Armenia
}

\begin{abstract}
Boundaries of national and international, typical and peculiar, individual and mass are ignored in the present conditions of battles (globalization, leakage of information, loss of technology, fast programs) and the observation and regeneration of architectural-spatial environments has become very important. The article observes the revelation of this problem with regeneration of architectural-spatial environment of Gyumri city. The goal is to determine modern approaches of observance of the peculiarity of cities. The problem is to study development demands of architectural-spatial environment in modern and historical cities, to study its perception mechanisms, the main factors and patterns.
\end{abstract}

\section{Introduction}

As a rule the principles of architectural psychology and environmental approach are absent. There are some problems about creation of architectural-spatial environment: ideological-artistic, compositional-artistic, stylistic, functional-designed and synthesis of all these to emotional, aesthetic scheme, which are responsible for the process of creating spatial forms.

\subsection{Return to tradition in architecture}

The main attention is focused on local peculiarity and observance of cultural heritage in modern architecture and its unity with main directions of modern architecture. The creation of local peculiarity in architecture, which reflects its environment and demands of time, asks for understanding of local, architectural heritage and use of previous design solutions, in order to comply with the conditions of the natural environment and social development. The architecture and its form is a tool of reflection of identity and difference. It reflects the harmony of modern endless form with local culture and climate. Each local culture is different with its climate, economy, level of development, traditions and all these must be observed in architecture. Architecture is not a reflection of unique environment, because the trend towards urbanization leads to the observance of the conflict of minimum

* Corresponding author: babakhanyans92@mail.ru 
specifications. As a result of technological and information development, in $20^{\text {th }}$ century, the architectural models began to spread over the world and pale the individual lines of cities, breaking the manuscript of originality and national peculiarity in architecture. The Western influence on architecture brought collapse of Western traditions and human nature. The modern cities become a collection of incomprehensible geometric blocks. The connection with the past has transformed. It is wrong to neglect the heritage of the past in scientific point, which is an element of national uniqueness and peculiarity and every kernel of society is a past level of civilization. The architecture is a part of civilization and is a proof of creative and aesthetic level of human development. There is a need to import solid and changeable values in architecture to reach the peculiarity. The natural environment and space, using their capabilities, modern construction means in combination with finance are solid value. And the final architectural image should be associated with the values of civilization and should reflect natural and cultural environment.

\subsection{The psychological aspects of urban peculiarity}

The change of role of cities in global context, their involvement in the rivalry, continuous change of urban social-cultural space, interurban migrations stipulate the requirement of phenomenon of urban peculiarity.

We need to distinguish these understandings "the peculiarity of city", "Urban peculiarity" and "Identification with city". The first is the notion of citizens about themselves, the second are similarities and differences of cities essence originality, peculiarity to other cities, the third is a psychological construct, the past of personalization, when the city perceived as a context of individual's life. In fact, from this perspective, the urban peculiarity is social identity. It is a social-cultural construct, which is formed in certain settlement. It is determined with receipt and reproduction of citizens lifestyle, traditions, norms, cultural symbols.

There are 3 factors, that impact on the formation of urban peculiarity:

1. Constant factors - location of city, climate, history

2. Variable factors - city size and population, exterior, living standard, cultural traditions

3. Symbolic factors - symbol of city, codes of mode of life, prominent persons, the nature of contacts in public.

The image of city is a system of interconnected and interactive signs, which includes its geographic architectural features: development history, population traditions, memorable events. The basis of symbolic component of urban peculiarity is an image of city. There are 2 understandings: "my city" (related to personal experiences and memories) and "Our city", which is the collective perception of city image identified with its values. In the process of forming the city image a spatial urban lexicon is formed, that characterizes the area. As a rule, urban lexicon intensifies and focuses formal details: famous place, local myths, local stories, city symbol, urban community.

Thus the theoretical bases of urban peculiarity, its formation factors and the factor of urban peculiarity were considered.

\section{Theoretical aspects of national architecture}

The originality of national architecture is defined by the totality of national indications, due to internal and external factors of cultural development: nature, history, life and everything, that affects to nation psychology and philosophy. External relations are also added to these. If the genetic roots of these contacts are identical, it gives a new quality to the local peculiarities. However, if national culture is perceived as an independent system, it can't be 
perceived as an example of national peculiarity. This culture could be solved in artificial ways, that fundamentally are contrary to the local culture. Today it is very common, widespread, many local cultures peculiarity put under question. The separate culture can not be recognized, if it doesn't reflect the typical character of the tradition system.

\subsection{The form and content of national architecture}

The national originality is the harmony of composition of architectural forms, based on the philosophy of aesthetic perception of national system, where the perception of tectonics, scale, proportion, materials are important related to the environment. If the architectural form is the expression of aesthetic content by the form, then it entirely refer to the system of national "form". For example, the constructiveness is the form of Armenian national architecture, but it doesn't mean that a constructive solution provides a nationality of building and makes it Armenian. The principals, individual forms are elements of the overall system. And such understandings of national architecture, as proportion, scale, tectonics or spatial solutions belong to the national concepts, which reflect the worldview of nations, largely determine its cultural identity. We often meet common lines in search of a national architecture features, that are identical for all nations, the difference is in primarily in architectural forms and their expression degree. There is no national culture without global lines, on the other hand, we can not say, that they are identical and it is the same in architecture. The most constant features are the lines in psychology, then the lines in architectural technological processes.

The Christian art is regular. The planning, constructive schemes, use of materials, even relief is very close in Russian, Byzantine, Georgian and Armenian architectures, but they always stood out with their national peculiarities.[1] The difference is in ideology and expression of the image in each architecture. And finally through the image of the world internal content of national architecture is expressed. Mostly it comes to the modern architecture, which is close to the form, but different to the content. The architectural content decides national peculiarity.

The architecture of 1950s was convicted for "decoration". In the 1960s, it became functional, constructive. Its forms reflected content, but the differences stayed and started to style modern elements.

The formal-spatial level in national architecture system is a hardly changeable kernel, which directly reflects people's macro space and micro space perception in urban and territorial solutions. Formal and spatial layers form the foundation, upon which the construction of national architecture as a unity of form and content is based.[1]

\subsection{The national and regional in architecture}

The borders of cultural peaks are the borders of national culture. Here the regional is fragmental. Here, the division of regional exclusively change into local factors, that is recognizable only by the national culture limits: relief, climate, building materials, confirmation.

The recognition of peculiarity of national architecture based on 3 "points" : nature, life, history (national and artificial environments, traditions, social side of the issue). All 3 aspects are merged and their boundaries are blurred. For example, Ararat and Shirak valley and the national architecture of North-Eastern regions are completely different principles. The first has open, spatial character of settlement, the second has close character, and the third has not the elements of first two aspects, here the houses are on the columns, with open ground floors, with high sloping roofs, and in the first two aspects there are flat roofs. 
The principal difference of regional and national is that the regional is structural factor and is a base for national. The character of regional is close, local, the character of national is global, transient. The national architecture is fully worldwide system, which is able to include some regional architectures. It is not necessary to view regional as a stage between local and national in the context of national architecture. The regeneration of national form, element, symbol, sign is acceptable in modern architecture. The semantic focus of traditions is characterized by generalized approach as an artistic form and function.

Japanese architect K. Tange calls to "destroy" the tradition, but in the same time don't exclude from modern architecture, but to reach its essence, to penetrate into it and to understand its mechanism structure and to develop in new content and form. In order to make the tradition ambivalent, it must negate, that is to "destroy".[1]

The national architecture is a certain tradition, but the tradition is not ambivalent. The synthesis of traditional and innovatory forms is a base of national architecture.

\subsection{The styling of national architecture}

It is difficult to decide a criterion of styling. It is frequent the retrospections of superior styling in architecture. They are two applicable phenomena: "stylisticness" and "stylization". The first is the use of old in modern architecture, the second is investment and current use of traditions in new architecture.[2] The stylization must not be viewed as a separate component, but it should be a part of the project idea.

\subsection{The national and typical}

Typical architecture is considered as the vulnerable part of Armenian architecture in 19501980ies. The national architecture, with individual formal solution as a basic condition of its creation, "encounters" with often-repeated typical "details". The modern architecture is close to folk architecture. The folk is the most regular, the most typical with morphological and semantic aspects. Here the most important thing is observance of architectonics. The architectonics is a interaction of architecture and the external environment. "Every architectural project is architectonic landscape bearer of unique image. It rises as a spiritual value, as it inspires land element modifying by tectonic ways",- A.Kaplun.

\section{The necessity of creation the peculiarity of architectural- spatial environment of Gyumri}

It is a common approach, that the high-speed rehabilitation construction in affected cities, which general aim is to provide the affected population with "roof". That is why there is a risk of peculiarity loss and it has been forgotten during the time. Gyumri is among these cities, which still reminiscent about disaster.

Gyumri is the second large city of Armenia. Its history begins from Ksenofon, BC $6^{\text {th }}$ century. During the middle ages, the Kumayri (Gyumri) becomes a large settlement and in 1840 during Russian-Persian war, it enters into Russian Empire. In 1837 Emperor Nikolay I visited this city and call it Alexandrapol, in honour of Empress Alexandra. A.Pushkin also visited this city.

As a result of economic and urban development, Alexandrapol became a center of commerce and crafts, the largest centre of Armenian culture in Transcaucasia (fig.1). 


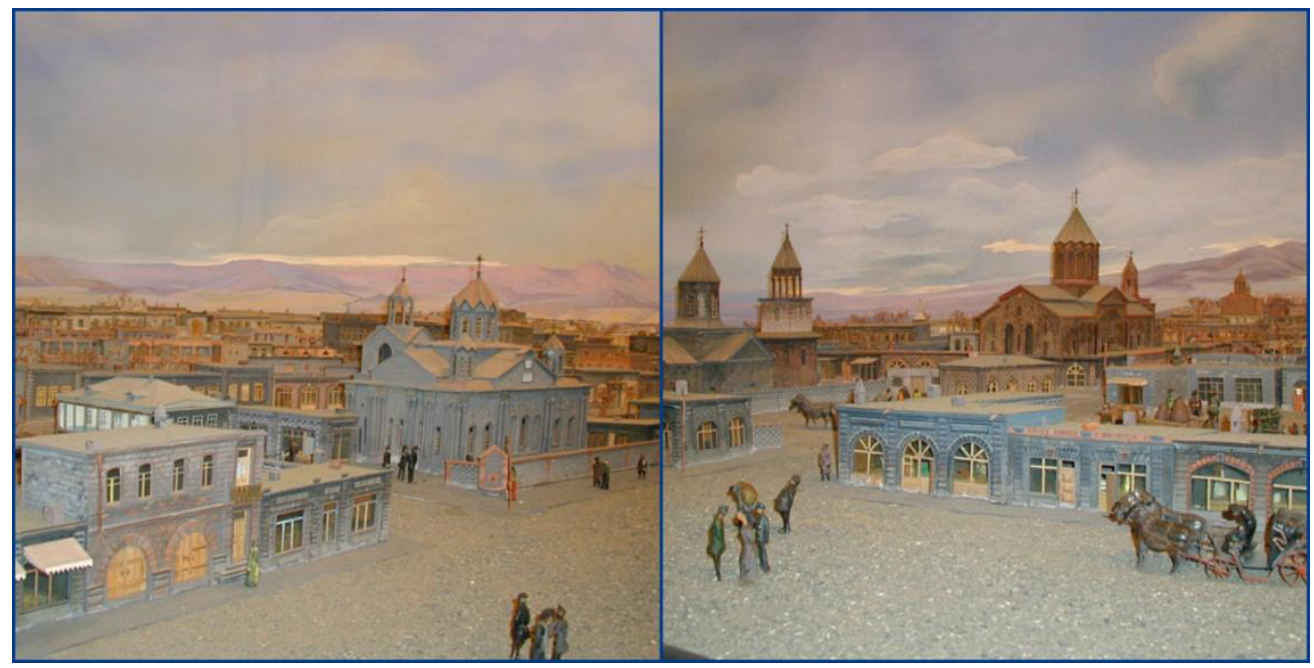

Fig. 1. Alexandrapol

The citizens are known with their sense of humor, observance of traditions, hard working and honor. In 1991 the city was renamed Gyumri. Many enterprises, schools, cultural centers had been constructed during the time, but in 1988 the destructive earthquake turned the city into ruins (fig.2) [11]. Two earthquakes hit Armenia on this day in 1988, killing 60.000 people and destroying nearly half a million buildings. The two tremors, only minutes apart, were measured at 6.9 and 5.8 in magnitude and were felt as far away as Georgia, Turkey and Iran. About 80 percent of the buildings failed to stand. The sheer scale of destruction overwhelmed the country's ability to respond. [10]

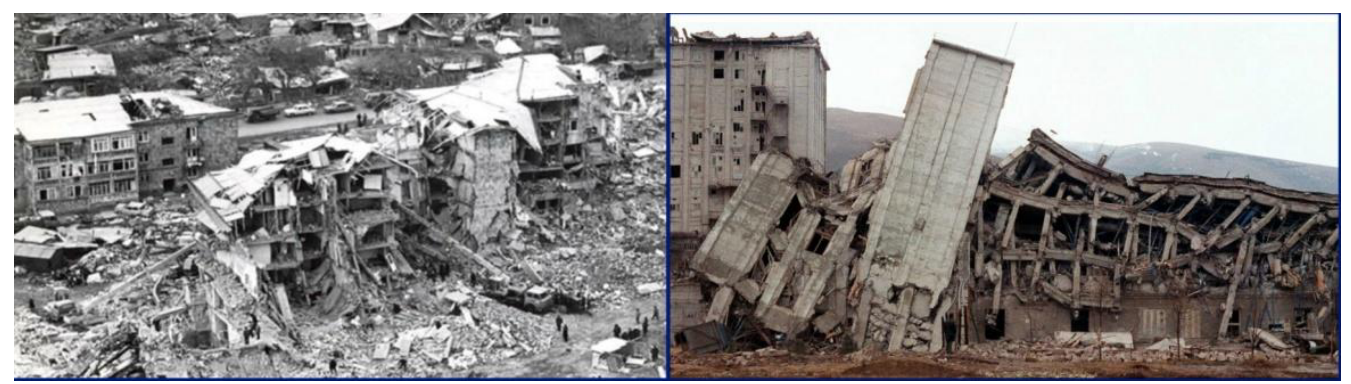

Fig. 2. Gyumri in 1988, after Spitak earthquake

The present-day villagers of Nalband, descendents of those who fled from Lower Basen, say the whole village levelled to the ground in a couple of seconds. People's lives have settled down but it differs significantly from what it was before. There was no unemployed family in the village before the quake; there was a garment factory with about 800 jobs; more than 200 people worked at the elevator plant in Spitak (about 10km far from Nalband). In addition, Nalband was a transit point for the Yerevan-Gyumri-Tbilisi railroad that used to take some of the Nalband villagers to their work in other places [13].

\section{Conclusion}

Despite its moderate size, this earthquake caused the largest earthquake disaster since the 1976 Tangshan earthquake in China. Official estimates, which the locals claim are grossly 
underestimated, give the following disaster statistics: dead - 25.000, injured -50.000 , evacuees - more than 100.000 , homeless -500.000 , in the epicentral region only 314 buildings collapsed, 641 needed to be demolished, 1264 needed repair or strengthening, 712 habitable after the earthquake [14].

Here, also the primary issue was to provide the people with accommodations (fig.3). But during 28 years, the issue of reconstruction of disaster zone limited with residential construction, which was devoid of architectural style and peculiarity. "The earthquake in Gyumri continues, for 28 years, we are living over and over again what happened within 41 seconds", said City Council member Levon Barseghian [15]. The industrial buildings weren't build, though this would provide jobs for population. Because of the bad social situation and endless presence of disaster, the population forgot about importance of peculiarity and tradition of city in his life.

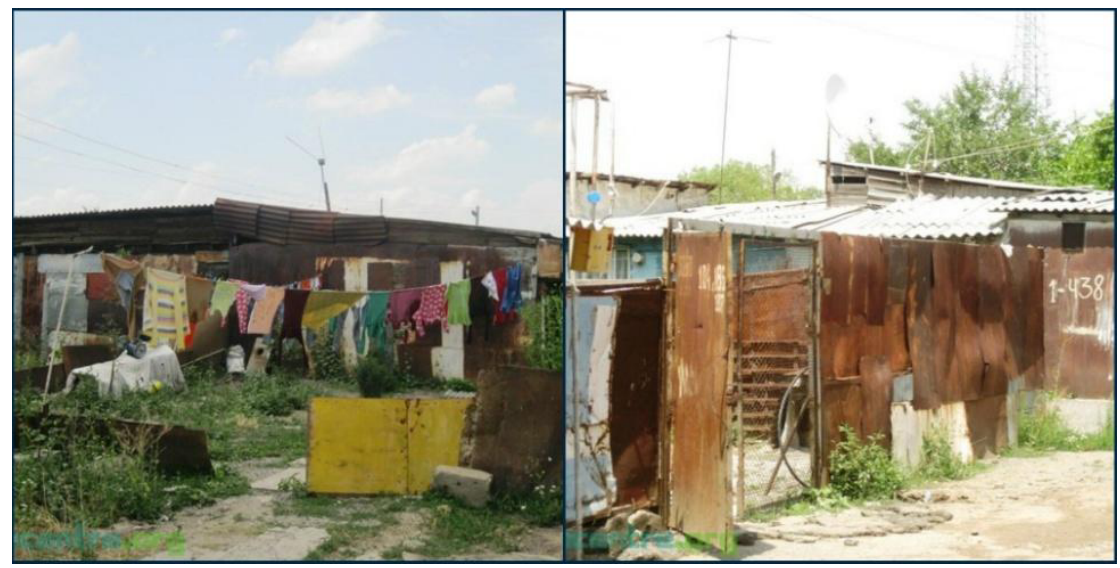

Fig. 3. Temporary dwelling in Gyumri, 2011

Thus the regeneration peculiarity of Gyumri is primary and important,[12] because the loss of such architectural-spatial environment sample with such peculiar description would be irrevocable for national architecture. The regeneration peculiarity of architectural-spatial environment of Gyumri is not an end in itself, but the goal is to create an environment, where the resident of Gyumri would regain himself and that environment would have its role in modern architecture with its peculiar and unique architecture.

\section{References}

1. K.V. Balyan, Modern National Architecture of Armenia, 186 (1987)

2. V.V. Shilin, Architecture and Psychology, 66 (2011)

3. A.V. Stepanov, Architecture and Psychology, 295 (1993)

4. I.S. Palyan, The lessons of Spitak earthquake and the problems of restauration of disaster zone, (1989)

5. A. de Botton, The Architecture of happiness, 280, (2010)

6. R. L. Gregory, Eye and Brain: The psychology of seeing, (1997)

7. V.V. Adamovich, Architectural design of public buildings and facilities, 543 (1984)

8. A. Kanatkin, Psychology of perception of architectural residential environment, (2010)

9. R. S. Nickerson, Psychology and Environmental Change, (2003)

10. S. Y. Balassanian, Retrospective analysis of the Spitak earthquake, 26, (1995) 
11. S. Harutyunyan, December of 1988,7 , (1990)

12. E. Khachiyan, The tragedy must not be reapeted, 264, (1998)

13. A. Harutyunyan, $A$ visit to the 1988 "center of the epicenter", (2014)

14. A.H.Hadjian, The Spitak, Armenia earthquake - Why so much destruction, (1992)

15. G. Abrahamyan, Residents Still Living the Spitak Earthquake, (2013) 